IN MEMORIAM

\title{
Dr. Norberto Sotelo Cruz
}

\author{
José G. López-Cervantes*
}

Coordinación de Especialidades Médicas; Presidente de la Academia; Departamento de Medicina y Ciencias de la Salud. Universidad de Sonora, Hermosillo, Sonora, México

Exponer la semblanza de mi querido colega, el Dr. Norberto Sotelo Cruz, es al mismo tiempo un ejercicio placentero, por lo destacado de su trayectoria, y triste, porque hemos perdido a un entrañable amigo y a un baluarte de la medicina científica. Toda su vida la desarrolló como un ser humano excepcional, que creó, transformó y construyó una obra de calidad profesional conducida con ética y moral en mano, que se reflejó en cada una de sus acciones.

Relatar la vida de un profesional e investigador como fue Norberto me emocionó al conocer su incansable trabajo. Su productividad científica recorrió un largo sendero que, con esfuerzo casi titánico e inteligencia, construyó su admirable conducta intelectual. Dicha productividad científica no debe analizarse solo como una escultura o una obra literaria, sino como un motivador para detonar trascendencia más allá de la simple admiración.

Desde el principio de su vida, su actuar denotaba su curiosidad innata. Norberto nació en Cumpas, un pueblo situado en el corazón del Estado de Sonora. De ahí su temperamento serio, casi adusto, pero con una sencillez y amabilidad que caracteriza al serrano de esa región. Fue el primero de siete hijos que Don Guillermo Sotelo y Doña Emma Cruz procrearon. Ambos progenitores fueron maestros de primaria, razón suficiente para que el ADN académico de Norberto estuviera presente en su código genético y se expresara constantemente durante toda su vida.

En las vacaciones de la primaria y de la secundaria en Cumpas, Norberto realizaba travesías por el pueblo con sus amigos, con resortera en mano, e iban tras los pájaros y las cachoras (lagartijas) desprevenidas, a las que hacía "necropsias campiranas" con el afán de saber lo que tenían adentro. Esta conducta de la vida dejaría huella.

La preparatoria la cursó en la Universidad de Sonora, en Hermosillo. En la capital del Estado, la figura de su tío, Don Federico Sotelo Ortiz, ortopedista de reconocido prestigio de esa época, le impactó. Estas dos imágenes, la disección y la figura del tío, fueron factores de influencia para que la medicina fuera su profesión.

La Facultad de Medicina de la Universidad Nacional Autónoma de México (UNAM) lo aceptó después de realizar su examen de admisión. Con excelente promedio, recibió su título de Médico Cirujano el 2 de abril de 1974. Después de terminar su internado rotatorio de posgrado en el Hospital de Guaymas, ingresó al Hospital 20 de Noviembre para realizar la residencia en rehabilitación. Durante su estancia de casi de 1 año en esa especialidad, el Dr. Quintal, jefe del servicio, reconoció su capacidad de aprender y enseñar, por lo que le dio amplio apoyo como instructor de los residentes del segundo año, aunque él era de primer año. Norberto no se sentía satisfecho, y fue durante la pasantía en pediatría de la propia residencia de rehabilitación cuando encontró el gran mundo de morbilidad que por lo regular afecta a ese grupo etario. Su interés por la atención a los niños no pasó inadvertido, por lo que el Dr. Villaraus, encargado de esa área, lo entusiasmó para que estudiara pediatría. El cambio no fue fácil, ya que estaba inscrito en la UNAM como residente en

\section{Correspondencia:}

*José Guillermo López-Cervantes

E-mail: memoloc25@ hotmail.com
Fecha de recepción: 20-11-2020

Fecha de aceptación: 06-12-2020 DOI: 10.24875/BMHIM.20000388
Disponible en internet: 24-02-2021 Bol Med Hosp Infant Mex. 2021;78(1):87-90 www.bmhim.com 1665-1146/@ 2020 Hospital Infantil de México Federico Gómez. Publicado por Permanyer. Este es un artículo open access bajo la licencia CC BY-NC-ND (http://creativecommons.org/licenses/by-nc-nd/4.0/). 
rehabilitación. Sin embargo, logró realizar el cambio a pediatría en el Hospital Infantil de México.

Al final de su tercer año de residencia se enteró de que se abriría un hospital infantil en la ciudad de Hermosillo. Para ingresar en este nosocomio le solicitaron dos cartas de recomendación de personalidades específicas de la pediatría. La primera la obtuvo del Dr. Dorantes Meza. La otra recomendación tendría que ser la del Dr. Kumate. Norberto se presentó ante él, con temor y miedo, y le solicitó la carta. Sin decir palabra alguna, el Dr. Kumate hizo el documento.

Cuando llegó a Hermosillo, Norberto mostró las dos cartas al Dr. Katase, director del Hospital Infantil del Estado de Sonora (HIES). Ocho meses después fue nombrado jefe del servicio de medicina interna.

Durante la visita, los residentes, en silencio absoluto y sin parpadear, veían cómo Norberto exploraba a los niños con acuciosidad y ternura. Sin ser meloso, comunicaba al niño lo que iba hacer. Su aspecto adusto y serio no impedía la empatía del niño, y más cuando la intención del Dr. Sotelo era conocer el porqué de esa expresión clínica de la enfermedad. Por las preguntas y la discusión, muchos residentes consideraban estas visitas como el momento más valioso de su aprendizaje. Después, en la sala de juntas, comentaban los casos de los pacientes y revisaban la literatura médica, además de solicitar pruebas de laboratorio o gabinete para asegurar el diagnóstico y verificar el seguimiento o la evolución de los pacientes. En estas sesiones se daban las propuestas para tesis o estudio de caso. En la interacción cotidiana siempre mostró a los residentes la disposición para intercambiar ideas y discusiones, sobresaliendo el juicio crítico y clínico, que dejaba huella no solo en el residente, sino también en el expediente clínico.

El ejercicio de la buena clínica quedó plasmado en el ordenado expediente clínico que Norberto exigía al residente. En las tesis de varios egresados está documentado ese legado de aprendizaje y los resultados de ese quehacer en el servicio de medicina interna.

Norberto forjó y motivó a sus colaboradores y residentes a manifestar sus hallazgos en escritos médicos. Su producción científica fue realmente impresionante: 199 publicaciones en revistas médicas especializadas, nacionales y extranjeras; 271 conferencias en congresos médicos nacionales y en el extranjero; 32 capítulos en libros de pediatría; y 65 tesis dirigidas de alumnos de especialidad médica, cuatro de maestría y tres asesorías de doctorado. También participó como revisor en varias revistas: Gaceta Médica de México, Cirugía y Cirujanos, Boletín Clínico del HIES, Boletín Médico del Hospital Infantil de México, American Journal of Tropical Medicine and Public Health,
Clinical Ophthalmology, Journal of Pediatric Neurology, Journal of Infectious Diseases y Revista de la Facultad de Medicina de Colombia, entre otras.

Esta productividad científica y académica le dio oportunidad de acceder y ganarse el reconocimiento de organismos e instituciones de prestigio reconocido. Fue miembro de varias academias, como la Academia Nacional de Medicina de México, la Academia Mexicana de Pediatría, la Academia Mexicana de Cirugía, la American Academy of Pediatrics, la New York Academy of Sciences, e Investigador Nacional Nivel 2, SNI.

El reconocimiento académico, su continua productividad y su carácter profesional le permitieron cumplir en tiempo y alta responsabilidad como jefe del servicio de medicina interna del HIES, director general del Hospital Infantil y de la Mujer del Estado de Sonora, jefe del Departamento de Medicina y Ciencias de la Salud de la Universidad de Sonora (UNISON), miembro del H. Junta Universitario, coordinador de Especialidades Médicas del Departamento de Medicina (UNISON), presidente de la Academia de Medicina, miembro de 17 sociedades médicas nacionales y del extranjero, miembro constituyente del Consejo Académico del HIES, presidente de la Asociación Médica del HIES, presidente de Asociaciones Civiles de Beneficencia y presidente fundador de la Agrupación para Niños Leucémicos y Afectados de Cáncer.

El Dr. Sotelo no se detenía en su constante actuación como pediatra, académico e investigador, sino que fue más lejos, al ser fundador (1984) de la revista del propio hospital, el Boletín Clínico del Hospital Infantil del Estado de Sonora, que a la fecha sigue vigente con sus dos números por año (Fig. 1). También participó como miembro constituyente y vocal de la Asociación Mexicana de Editores de Revistas Biomédicas (19972013), miembro de la World Association of Medical Editors (2001-2017), miembro de la European Association of Science Editing (2015-2017), miembro del consejo editorial del Boletín Médico del Hospital Infantil de México, vicepresidente y presidente de la Asociación Mexicana de Editores de Revistas Biomédicas (2013-2017), representante del capítulo México de la European Association of Science Editing (2015-2017) y miembro del comité editorial de la Revista Buena Salud Federación Médica de Sonora.

Un personaje de la dimensión del Dr. Sotelo no pasaba inadvertido, y su productividad como pediatra, como maestro, como investigador y como conductor de muchas responsabilidades de alta envergadura le hicieron merecedor de diversas distinciones (Fig. 2): Reconocimiento al Mérito, Hospital Infantil del Estado de Sonora (1983); Premio Ixtliton de Oro, México, D.F. 


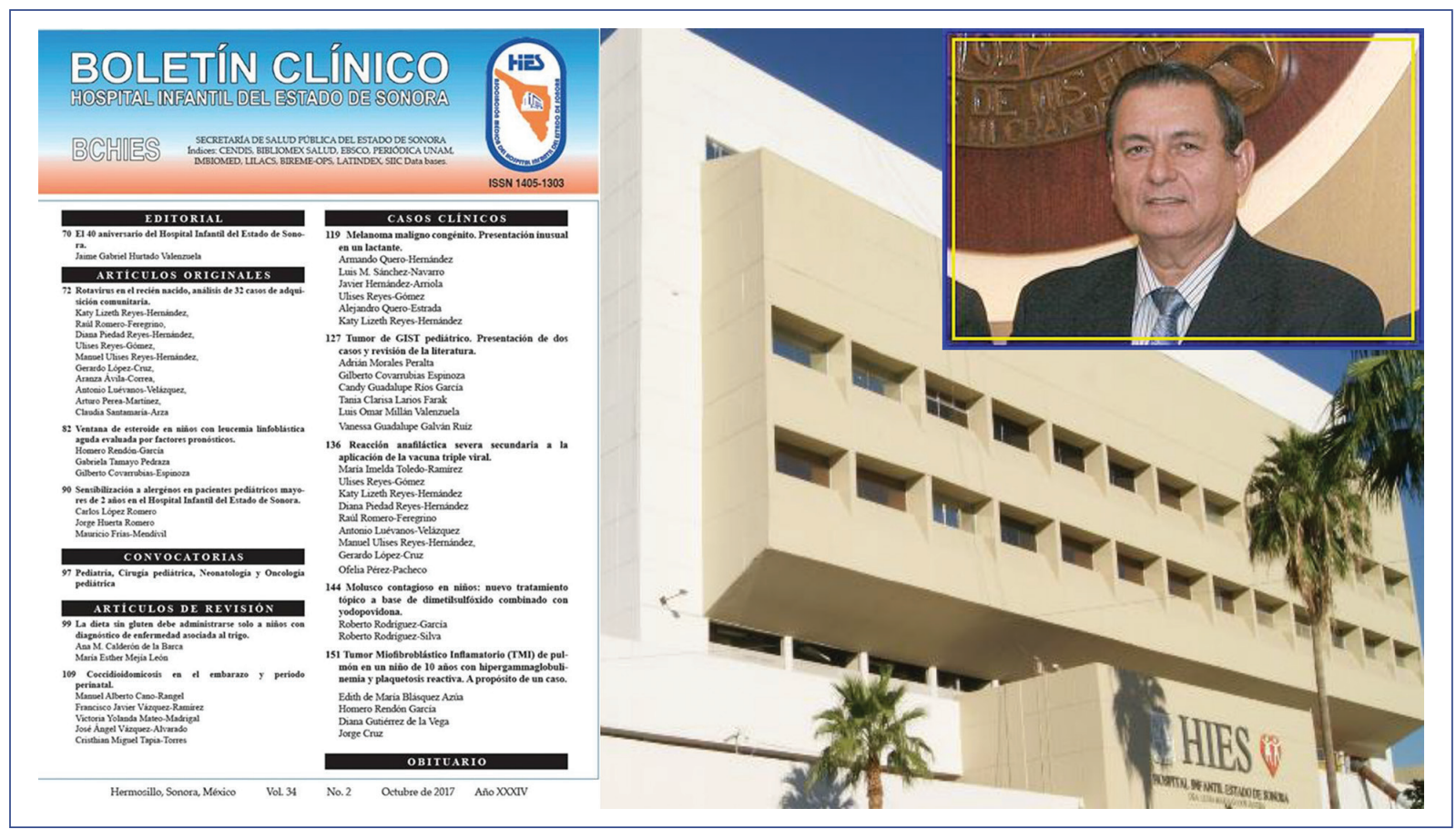

Figura 1: El Hosptial Infantil del Estado de Sonora, nosocomio donde el Dr. Sotelo llevó a cabo su productivad asistencial y académica: como médico y jefe del servicio de Medicina Interna y un periodo de seis años como Director. Como editorialista, inició al fundar el Boletín Clínico del Hospital Infantil del Estado de Sonora en 1984, que sigue vigente.

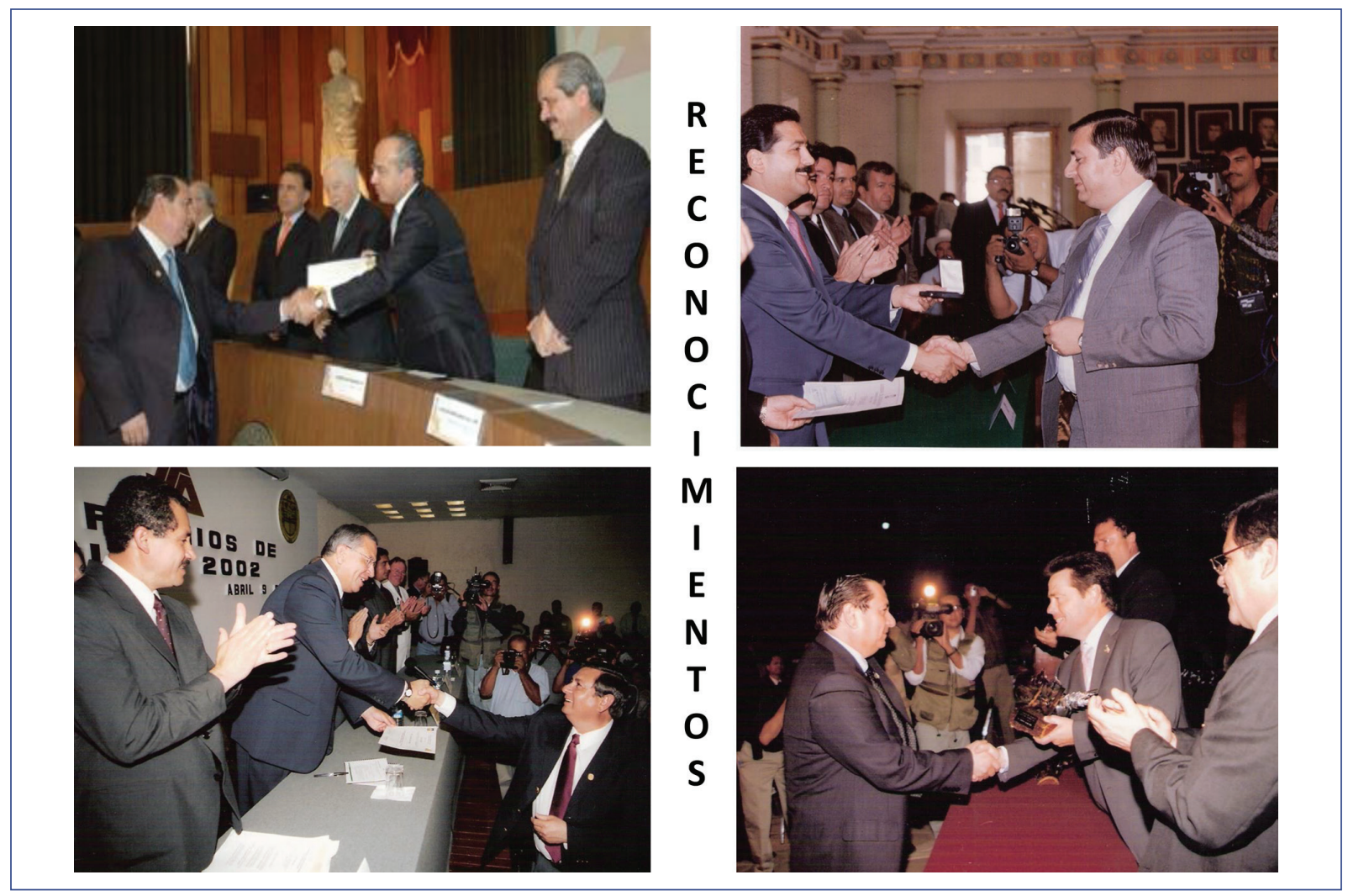

Figura 2: Su trayectoria asistencial, académica y científica recibió reconocimientos al mérito por el presidente Calderón, y los gobernadores de Sonora, el Lic. López Nogales, Lic. Beltrones e Ing. Bours. 


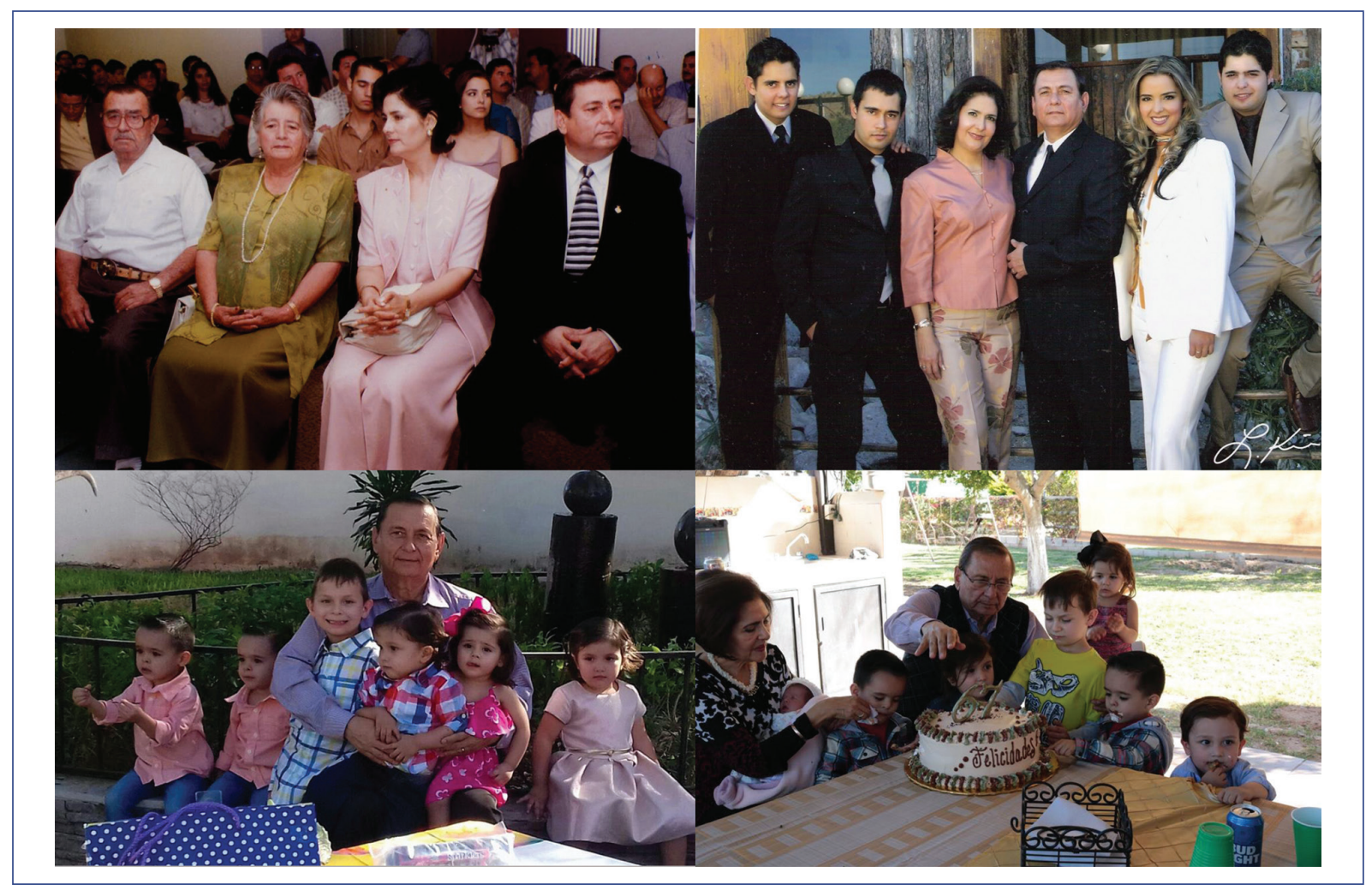

Figura 3: La familia para el Dr. Sotelo fue parte angular de su vida. Con sus padres y su esposa, Leticia Medina (arriba e izquierda); con sus hijos profesionistas, Luis Adrián, Demetrio, Ana Bolena y Bruno (arriba y derecha); los nietos: Bruno, Norberto, Massimo, Vicente, Renata y Doménica (abajo).

(1986); Premio de Investigación Gastón Madrid, Hermosillo, Sonora (1991); Premio Federico Gómez, México, D.F. (1993); Reconocimiento del Gobierno del Estado de Sonora (1994); Premio PROCEFF a la Investigación Pediátrica, Sociedad Mexicana de Pediatría, México, D.F. (1998); Medalla al Mérito Dr. Alfonso Pruneda por 25 años de servicio (2003); Medalla al Mérito Dr. Maximiliano Ruiz Castañeda por 30 años de servicio (2007); Premio de Investigación Dr. Gastón Madrid, y Reconocimiento al Desempeño Médico Categoría de Excelencia, Presidencia de la República.

Norberto no solo seguía el análisis de la ciencia, sino que mostraba en su actuar la medicina basada en la evidencia. Este último argumento, junto con su humanismo, lo reflejaba al estudiar a sus pacientes. Si no podía darle seguimiento a un paciente en su hospital y tenía que trasladarse a otra institución para su estudio o tratamiento, él hacía todo lo posible para obtener dicho recurso o apoyo para hacerlo. Por otro lado, mostraba una «obsesión» por determinar con precisión un diagnóstico difícil.
En síntesis, el Dr. Sotelo promovía reducir el puente entre el clínico y el investigador. Su idea era colocar la forma de pensar del investigador en correlación con la del médico al observar el paciente.

La hermosa familia que formó Norberto la dejé para el final, porque considero que es la joya de la corona. Sin duda alguna, su esposa, Dña. Leticia Medina, fue el motor y la intermediaria para dar al Dr. Sotelo la chispa que brilla no solo afuera sino también adentro del seno familiar, además de apoyarle en su vida cotidiana de médico, maestro e investigador. Cuatro hijos ya profesionales son el producto valioso de esa unión matrimonial: Demetrio, Ana Bolena, Luis Adrián y Bruno Norberto. Ellos dieron a Norberto un plus de alegría al hacerle abuelo de siete nietos, con quien pasó los últimos meses de su vida en estrecha convivencia (Fig. 3).

El vacío que deja el Dr. Norberto Sotelo es enorme, pero somos afortunados porque su legado académico y científico es suficiente para imitarle y recordarle constantemente. 